\title{
Signaling in Parasitic Nematodes: Physicochemical Communication Between Host and Parasite and Endogenous Molecular Transduction Pathways Governing Worm Development and Survival
}

\author{
James B. Lok ${ }^{1}$ \\ Published online: 7 October 2016 \\ (C) The Author(s) 2016. This article is published with open access at Springerlink.com
}

\begin{abstract}
Signaling or communication between host and parasite may occur over relatively long ranges to enable host finding and acquisition by infective parasitic nematode larvae. Innate behaviors in infective larvae transmitted from the soil that enhance the likelihood of host contact, such as negative geotaxis and hypermotility, are likely mediated by mechanoreception and neuromuscular signaling. Host cues such as vibration of the substratum, elevated temperature, exhaled $\mathrm{CO}_{2}$, and other volatile odorants are perceived by mechanosensory and chemosensory neurons of the amphidial complex. Beyond this, the molecular systems that transduce these external cues within the worm are unknown at this time. Overall, the signal transduction mechanisms that regulate switching between dauer and continuous reproductive development in Caenorhabditis elegans, and doubtless other freeliving nematodes, have provided a useful framework for testing the hypotheses about how the morphogenesis and development of infective parasitic nematode larvae and the lifespan of adult parasites are regulated. In C. elegans, four major signal transduction pathways, G-protein-coupled receptor signaling, insulin/insulin-like growth factor signaling, TGF $\beta$ like signaling, and steroid-nuclear hormone receptor signaling, govern the switch between dauer and continuous development and regulate adult lifespan. Parasitic nematodes appear to have conserved the functions of G-protein-coupled signaling, insulin-like signaling, and steroid-nuclear hormone
\end{abstract}

This article is part of the Topical Collection on Parasitology

James B. Lok

jlok@vet.upenn.edu

1 Department of Pathobiology, School of Veterinary Medicine, University of Pennsylvania, 3800 Spruce Street, Philadelphia, PA 19104, USA receptor signaling to regulate larval development before and during the infective process. By contrast, TGF $\beta$-like signaling appears to have been adapted for some other function, perhaps modulation of the host immune response. Of the three signal transduction pathways that appear to regulate development in parasitic nematodes, steroid-nuclear hormone signaling is the most straightforward to manipulate with administered small molecules and may form the basis of new chemotherapeutic strategies. Signaling between parasites and their hosts' immune systems also occurs and serves to modulate these responses to allow chronic infection and downregulate acute inflammatory responses. Knowledge of the precise nature of this signaling may form the basis of immunological interventions to protect against parasitism or related lesions and to alleviate inflammatory diseases of various etiologies.

Keywords Parasitic nematode · Signal transduction · Insulin · $\mathrm{TGF} \beta \cdot$ Nuclear receptor $\cdot$ G-protein

\section{Introduction}

On a global scale, parasitic nematodes exact enormous tolls on human health and on animal agriculture and animal welfare [1]. Currently, there are no effective vaccines against parasitic nematodes, and as a group, the armamentarium of drugs that can be brought to bear on parasitic nematode infections is relatively small. Especially in the veterinary field, this panel of drugs is threatened by burgeoning, genetically based resistance in parasite populations $[2,3]$. Thus, discovery of novel drug and vaccine targets in pathogens is imperative. Existing anthelmintic drugs against parasitic nematodes may be broadly categorized as neuromuscular agents affecting cholinergic neurotransmission [4], hyperpolarizers of neuromuscular synapses [5], tubulin-binding agents, and metabolic inhibitors [6]. 
It is likely that refinements in knowledge about these classes of drugs and the molecular structures of their targets will enable new drugs within those categories to be brought on line. However, it is also significant that there is increasing appreciation of the potential for essential parasite-specific signaling mechanisms to act as chemotherapeutic targets, particularly those mechanisms that involve interaction of small molecule ligands with cellular receptors [7]. Thus, the practical rationale for investigating signaling mechanisms within parasitic nematodes is strong. Also crucial to basic scientific importance is an understanding of how parasitic nematodes have adapted key signaling mechanisms from free-living ancestors to the evolution of animal parasitism.

Contemporary biologists tend to equate signaling with molecular mechanisms and pathways of cellular signal transduction. However, this review will define signaling broadly to include known mechanisms by which parasitic nematodes perceive environmental factors that aid in host finding and acquisition and by which they communicate with other parasites and with their hosts, in addition to the molecular pathways that transduce these signals within and between cells of the parasite. This distinction is crucial given the reliance of molecular studies of parasitic nematodes on science pertaining to Caenorhabditis elegans as a source of hypotheses for testing. Of the active areas of signal transduction research in C. elegans, TGF $\beta$ [8], insulin and insulin-like growth factor [9], nuclear receptor [10], and Gprotein-coupled receptor (GPCR) [11] signaling have received the greatest attention from parasitologists owing to their essential functions in regulation of dauer development in C. elegans. Dauer development is regarded as a paradigm for regulation of infective larval development before and during host invasion in parasitic nematodes $[12 \bullet \bullet, 13]$. As tools for functional genomic study in parasitic nematodes become more sophisticated and widely used, the extensive knowledge of chemoreceptors in sensory neurons of $C$. elegans will likely be applied to parasite biology based on the likely functions of their homologues in host finding by soil-transmitted parasitic nematodes [14]. This review will examine the adaptation of these relevant signaling mechanisms from C. elegans to the requirements for the evolution of parasitism in nematodes, and it will examine other external cues, many originating from the host, that are likely essential for parasitic nematode life cycles, indicating, or hypothesizing where possible, the mechanisms by which these cues are processed within the worms at the neuronal and molecular levels. The article will conclude with a critique of these pathways as chemotherapeutic targets.

\section{Physicochemical Signals From Host to Free-Living Infectious Stages-Host Finding}

Prior to encountering a host, infective third-stage larvae of soil dwelling parasitic nematodes (iL3) undertake innate behaviors that increase their chances of contacting a host (Fig. 1, Table 1). One such behavior is crawling upwards in water films on stationary objects. Such behaviors are common in skin-penetrating iL3, such as Strongyloides stercoralis and various hookworms, which climb to the apices of vegetation or prominences in the soil, and in passively ingested iL3 such as those of Haemonchus contortus, which crawl to the ends of grass blades $[15,16]$. Skin-penetrating S. stercoralis and Ancylostoma caninum (hookworm) iL3 clearly exhibit true negative geotaxes, whereas those of the passively ingested $H$. contortus do not [17]. Interestingly, iL3 of Oesophagostomum dentatum, which are also passively ingested by their porcine hosts, exhibit an agedependent shift in geotactic behavior in which 4-day-old iL3 show no geotaxis while 8-day-old larvae exhibit a positive geotaxis, tending to crawl downwards [18]. This may represent a behavioral adaptation by which older larvae position themselves in the moist soil where they are protected from desiccation and more liable to be ingested by rooting pigs. The neuronal and molecular bases for these crucial taxes in host finding are currently unknown, but it might be inferred from C. elegans science that they are mediated by touch receptors. Neurons called microtubule cells, which are lodged between the cuticle and underlying epidermis, detect tactile and seismic stimuli in C. elegans. C. elegans also uses these microtubule cells to receive delocalized mechanical signals such as substrate vibration. This system may also provide a model of mechanosensory aspects of the infective process in skin-penetrating nematode parasites. L3i of some species appear to use soil vibration to detect the approach of a host [19]. Identifying mechanoreceptors in parasitic nematodes and ablating them by microlaser surgery $[20,21]$ or by cell-specific expression of recombinant lytic factors [22] in an appropriate parasitic nematode model may confirm the role of mechanosensation in innate behaviors that foster host acquisition.

Another innate behavior that increases the likelihood of skin-penetrating L3i establishing contact is a shift from rest to motile or hypermotile behavior at the approach of a host. It is assumed that the requisite change in motility would have to occur prior to when contact is imminent in response to hostassociated cues, such as vibration of the substratum [19, 23], volatile chemicals [14], and elevated temperature [19, 23], that act over relatively long ranges (Fig. $1 \mathrm{~B}$, Table 1). It is likely that responsiveness to seismic cues of host approach is mediated by mechanosensory neurons as discussed above. Orientation toward mammalian hosts by migrating up temperature gradients appears to be conserved in diverse skinpenetrating iL3 that dwell in contaminated soil such as A. caninum [23] and S. stercoralis [24]. Results of cell ablation reveal that ALD class neurons in the amphids are necessary for thermotaxis by $S$. stercoralis [24]. Exhaled $\mathrm{CO}_{2}$ has long been considered a candidate for such a long-range host odorant cue, and its status as a stimulus for motility shift on host approach has been confirmed for skin-penetrating iL3 of $S$. stercoralis 


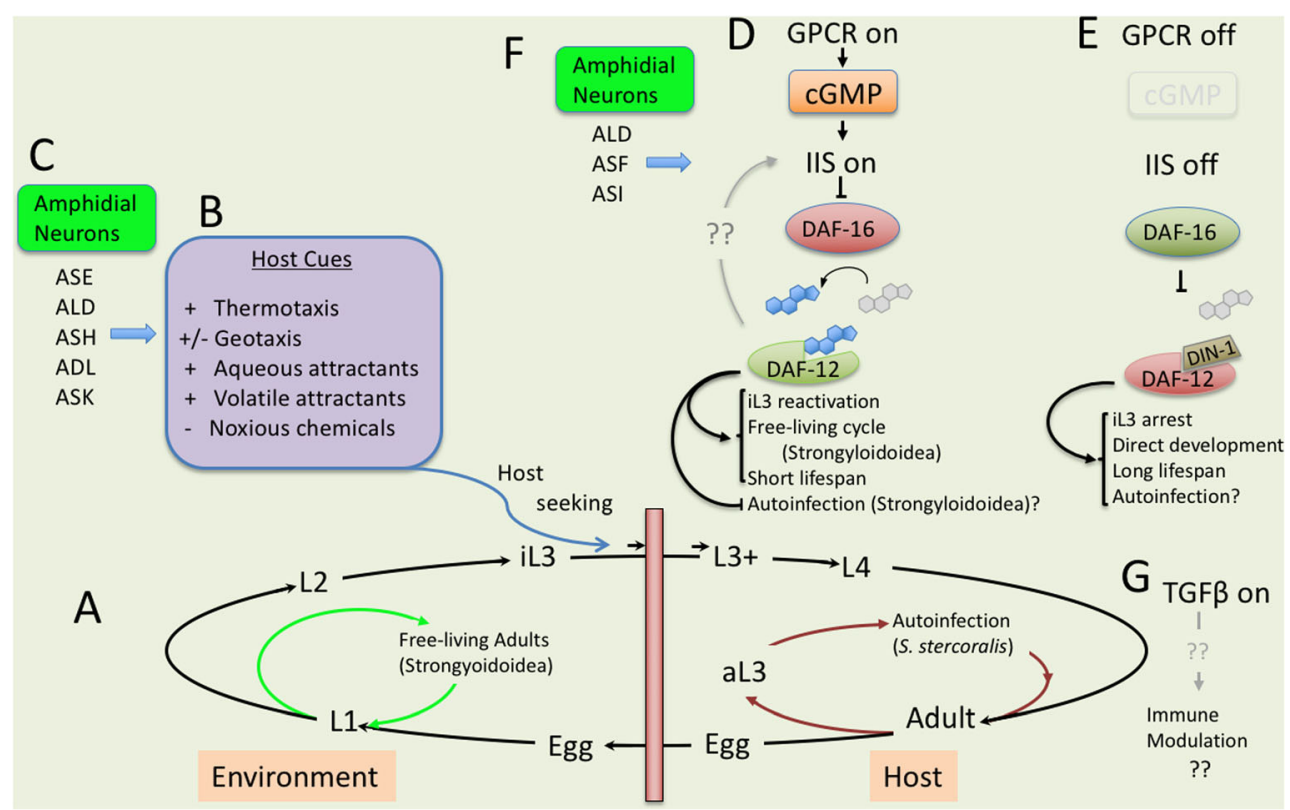

Fig. 1 Control of host finding and development by infective third-stage parasitic nematode larvae (iL3). A Generalized developmental diagram for parasitic nematodes. Includes free-living and autoinfective alternatives in the Strongyloidoidea. $B$ Innate behaviors and hostassociated cues mediating host finding and acquisition by iL3. $C$ Amphidial sensory neurons mediating innate behaviors and responsiveness to host cues. $D$ Coordinated G-protein-coupled (GPCR), insulin/insulin-like growth factor (IIS), and DAF-12 nuclear hormone receptor signaling. Note: Active GPCR and IIS (signaling "on") negatively regulate the forkhead transcription factor DAF-16 and promote synthesis of DAF-12 ligands (blue steroid icon) from dietary cholesterol (gray steroid icon). Upregulation of putatively agonistic insulin-like peptides by the DAF-12 ligand suggests possible feedback

and $A$. caninum and the passively ingested iL3 of $H$. contortus [25]. L3i of the skin-penetrating species respond to $\mathrm{CO}_{2}$ at a concentration approximating that found in exhaled breath $(3 \%)$ with increased but nondirectional crawling activity. By contrast, $H$. contortus iL3 virtually cease progressive movement in the presence of physiological $\mathrm{CO}_{2}$ levels, remaining motile but tightly coiled. Both of these responses are saturable at high concentrations of $\mathrm{CO}_{2}$, and $\mathrm{H}$. contortus iL3 that become nonmotile at high concentrations of $\mathrm{CO}_{2}$ regain progressive motility within approximately $30 \mathrm{~s}$ of transfer to ambient air. The molecular mechanisms underlying the $\mathrm{CO}_{2}$ responses of these infective larvae are currently unknown, but their saturability and reversibility are consistent with mediation by a cellular receptor [25]. Thus, $\mathrm{CO}_{2}$ constitutes a long-range chemical cue for specific behavioral modifications that would enhance host contact in skin-penetrating L3i and in passively ingested ones. Presumably, hypermotility would serve to increase host contacts by the former, which must actively acquire the host, and reduction or loss of motility by the latter would serve to maintain their positions at the apices of grass blades and other plant structures where ingestion by grazing herbivores would then be likely. This overall interpretation of host-elicited behaviors has been upheld by more comprehensive comparative of IIS by DAF-12 signaling in S. stercoralis. This confers resumption of development by iL3, free-living development in Strongyloidoidea and may shorten adult lifespan and suppress autoinfection in Strongyloides stercoralis. E GPCR, IIS, and DAF-12 signaling in the "off" state confer iL3 arrest, direct development of L1 to iL3, and autoinfection in $S$. stercoralis. F Amphidial neurons mediating resumption of iL3 development and switching between parasitic and free-living alternatives in $S$. stercoralis. $G$ Although TGF $\beta$-like signaling is conserved in parasitic nematodes, expression patterns of ligands during development are inconsistent with conservation of $C$. elegans-like TGF $\beta$ function in parasitic nematodes. Alternative functions hypothesized include modulation of host immunity

study of parasitic nematodes from diverse phyla, including species infecting arthropods and mammals [26•].

As an interesting example of convergent evolution, it appears that host preference is a stronger factor than phylogeny in determining sensitivity to specific olfactory cues. For example, L3i of the rodent parasite Strongyloides ratti is more similar to iL3 of the distantly related Nippostrongylus braziliensis in its profile of responses to a large panel of olfactory cues than it is to iL3 of its cogener $S$. stercoralis [26•], a parasite of humans and dogs. In an even more striking example, it appears that parasitic nematodes and blood-sucking arthropods exploit similar volatile odorants to help them orient to their hosts. iL3 of $S$. stercoralis are attracted to diverse human-associated odorants, and among the most active of these are 2- and 3-methyl-1-butanol, 3-heptanol, and 1nonanol, which are all potent attractants for host-seeking mosquitoes (Table 1) [26•].

\section{Orientation on the Host Once Acquired}

Once contact with the host has been established, orientation of larvae from the pelt onto the skin and location of optimal sites 
Table 1 Summary of behaviors associated with host finding and acquisition, their mediation by host cues and, where known, the amphidial neurons required for their perception

\begin{tabular}{|c|c|c|c|c|c|}
\hline Behavior & Host cue category & Parasites studied & Active compounds & $\begin{array}{l}\text { Amphidial } \\
\text { neurons involved }\end{array}$ & References \\
\hline Geotaxis (positive) & None-innate behavior & $\begin{array}{l}\text { S. stercoralis } \\
\text { H. contortus }\end{array}$ & NA & $? ?$ & {$[15,16]$} \\
\hline Geotaxis (negative) & None_-innate behavior & O. dentatum & NA & $? ?$ & [18] \\
\hline \multirow[t]{3}{*}{ Hypermotility } & Vibration of substratum & A. caninum & NA & $? ?$ & {$[19,23]$} \\
\hline & Elevated temperature & A. caninum & NA & $? ?$ & {$[19,23]$} \\
\hline & & S. stercoralis & NA & ALD & {$[24]$} \\
\hline \multirow[t]{3}{*}{ Nictation $^{\mathrm{a}}$} & Elevated temperature & S. stercoralis & NA & ALD & {$[14,24,26 \bullet]$} \\
\hline & & $\begin{array}{l}\text { S. ratti } \\
\text { N. brasiliensis }\end{array}$ & NA & $? ?$ & {$[26 \bullet]$} \\
\hline & & H. contortus & & & \\
\hline \multirow[t]{6}{*}{ Approaching the host } & Volatile odorants & S. stercoralis & $\mathrm{CO}_{2}$ & $? ?$ & {$[25]$} \\
\hline & & $\begin{array}{l}\text { S. stercoralis } \\
\text { S. ratti }\end{array}$ & $\begin{array}{l}\text { Numerous } \\
\text { host skin-associated cues }\end{array}$ & $? ?$ & {$[26 \bullet]$} \\
\hline & & N. brasiliensis & & & \\
\hline & & H. contortus & & & \\
\hline & Thermal gradient & S. stercoralis & NA & ALD & {$[23,24,26 \bullet]$} \\
\hline & & A. caninum & NA & $? ?$ & \\
\hline \multirow[t]{3}{*}{ Orientation on the host } & Aqueous attractants and repellants & S. stercoralis & $\mathrm{NaCl}$ & ASE, ASH & {$[27,28]$} \\
\hline & & & Urocanic acid & $? ?$ & [29] \\
\hline & & & SDS — noxious stimuli-avoidance & ASH, ADL & {$[30,31]$} \\
\hline
\end{tabular}

A.-Ancylostoma, H.-Haemonchus, O.-Oesophagostomum, N.-Nippostrongylus, S.—Strongyloides

${ }^{a}$ Nictation is a behavior in which nematodes stand on their tails, often in aggregates, thus further elevating themselves above the substratum to promote host contact

for penetration may be mediated by continued thermotaxis, and orientation in response to both aqueous and volatile chemicals (Fig. 1 B, Table 1). Transduction of aqueous host cues by specific chemosensory neurons in the amphids appears largely conserved between the free-living $C$. elegans and the phylogenetically distant parasite $S$. stercoralis. Cell ablation studies in $S$. stercoralis confirm that neuron pair ASE mediates attraction of $\mathrm{L} 3 \mathrm{i}$ to optimal $\mathrm{NaCl}$ concentrations and that neuron pair ASH mediates repulsion from high salinity [27]. Notably, the positional homologues of these neurons in C. elegans, ASE and ASH, also mediate attraction to $\mathrm{NaCl}$ and repulsion from high osmolality, respectively (Fig. 1 B, C; Table 1) [28]. Most putative aqueous attractants from host skin such as $\mathrm{NaCl}$ have been selected for study based on the premise that they are known components of skin or secretions therefrom. By contrast, an unbiased scheme for fractionation of a crude extract of canine skin that was attractive for iL3 of $S$. stercoralis revealed that urocanic acid, a common component of human and other mammalian skin, accounted for the majority of this attractancy [29].

Avoiding noxious or harmful chemicals is also advantageous for parasitic iL3 in the environment and on the host. Responses to sodium dodecyl sulfate (SDS) have been used as a model for this type of behavior in A. caninum whose iL3, migrating on agar layers, avoid droplets of $1 \%$ SDS, quickly reversing the direction of movement and migrating away. Ablation of neuron pairs ASH and ADL eliminates this rearward avoidance response by A. caninum iL3, actually increasing the speed of forward migration in the presence of SDS [30]. In C. elegans, amphidial neuron pairs ASH and ASK mediate chemical avoidance [31], indicating at least partial conservation of neuronal control of noxious chemical avoidance by free-living and parasitic nematodes.

\section{Environmental Cues Governing Morphogenesis and Development of Infective Parasitic Nematode Larvae}

Morphological and behavioral similarities between the iL3 of parasitic nematodes, particularly the soil-transmitted species, and dauer third-stage larvae of $C$. elegans have been recognized for decades $[13,32]$. The majority of parasitic iL3 are like $C$. elegans dauers in that they are radially constricted in overall body profile, have narrow pharynxes, are nonfeeding, and have modified, chemically resistant cuticles. More 
importantly, parasitic iL3, like C. elegans dauers, are in a state of developmental arrest and require entry into the definitive host for reactivation (Fig. 1). Moreover, theoretical parallels drawn between molecular regulation of iL3 morphogenesis and development and C. elegans dauer regulation have been largely substantiated in parasitic nematodes by genomic and transcriptomic evidence and, in the few instances where direct interrogation of gene or protein function is possible, by experimentation [12••]. Dauer development in C. elegans is a conditional response to environmental stressors including overcrowding with con-specific nematodes, declining food levels and elevated temperature $[32,33]$.

The majority of parasitic nematode species develop through an invariant pattern of first through third larval stage development in the environment extrinsic to the host, infection of the host as iL3 and development through two additional molts to the adult stage, and then localization to some predilection site within the host body (Fig. 1 A). In these life histories, development to the iL3 is fixed and there are no equivalents of the life cycle switching between developmental fates exemplified by the checkpoint governing dauer versus continuous development in C. elegans. By contrast, first-stage larvae (L1) of members of the Strongyloidoidea, including the genera Strongyloides and Parastrongyloides, are capable of switching between direct development to iL 3 or development to one or more generations of free-living males and females (Fig. 1 A). Most species of Strongyloides execute only one generation of free-living development, with the progeny of free-living males and females developing exclusively to the iL3. However, Strongyloides planiceps can undertake up to nine sequential generations of free-living development, with increasing attrition to the parasitic cycle in each [34] and Parastrongyloides spp. can develop through an indefinite number of free-living generations as a free-living nematode but switch to formation of iL3 to infect a marsupial host in response to changing environmental conditions [35]. The switch between free-living and parasitic alternatives in the Strongyloidoidea appears to be governed by factors similar to those governing dauer switching in C. elegans, but in ways that are frequently contrary to the $C$. elegans responses. For example, while high temperatures predispose $C$. elegans toward dauer development, the majority of Strongyloides spp. L1 exhibit the opposite response, developing more frequently to free-living adults at elevated temperature [36, 37]. The exception to this generalization is $S$. stercoralis, where temperatures approaching host body temperature $\left(34-37^{\circ} \mathrm{C}\right)$ promote direct development to iL3 while lower temperatures promote free-living development. As did chemotaxis, this temperature-dependent developmental switch in $S$. stercoralis requires signaling by ALD class amphidial neurons [38]. Additional neuronal inputs from amphidial neurons ASF and ASI are required to regulate this switch (Fig. $1 \mathrm{~F}$ ) [20]. Consistent with dauer switching in C. elegans, depletion of nutrients in the environments of postparasitic larvae promotes direct development to iL3 and enrichment of these in culture media promotes development to free-living adults in Strongyloides spp. [39-41].

\section{Cellular Signaling Pathways Mediating Morphogenesis and Development of iL3 in Parasitic Nematodes}

Four cellular signal transduction pathways regulate dauer development and the associated property of lifespan extension in C. elegans. Thermal cues and chemical signals of food level and population density in the local environment are received by G-protein-coupled receptors (GPCRs) in chemo- and thermosensory neurons in the amphids [42-45]. Dauer regulatory signals from GPCRs in the amphids are transduced downstream by parallel insulin/insulin-like growth factor (IIS) $[9,33]$ and TGF $\beta$ pathways $[8,33]$, and these pathways converge on a steroid-nuclear hormone receptor (NHR) pathway involving the DAF-12 NHR and its dafachronic acid ligands [46-51]. In general, experimental evidence discussed in the following paragraphs supports that GPCR, IIS, and steroid-NHR signaling function to regulate the infective process in parasitic nematodes in ways that are consistent with their functions in regulating dauer development in C. elegans (Fig. 1 D, E; Table 2). By contrast, the limited data available suggest that TGF $\beta$ has been adapted for functions in parasitic nematodes that are fundamentally different from the dauer regulatory role of this signaling pathway in C. elegans (Fig. 1 G, Table 2) [12••].

Genomic and transcriptomic studies support that elements of GPCR signaling that regulate dauer development in C. elegans are conserved in parasitic nematodes (Table 2) $[52,53]$. Gene homologues of gpa-2 and gpa-3, whose products mediate dauer pheromone signals in C. elegans, have been cloned from the genome of S. stercoralis [54], and the transcriptome of $S$. stercoralis contains homologues of mRNAs encoding key elements of GPCR signaling in C. elegans including $C e-d a f-11$ (encoding a guanylyl cyclase), $C e$-tax-2, and Ce-tax-4 (encoding $\alpha$ and $\beta$ subunits of a neuronal cyclic nucleotide-gated ion channel). These homologues were designated $S s$-gyc-11, Ss-tax-2, and Ss-tax-4, respectively [53]. Experimental evidence that GPCR signaling governs development by iL3 of parasitic stems from pharmacological studies in which a cell-permeable analog of cGMP, 8-bromocyclic GMP, stimulates resumption of development by cultured iL3 of A. caninum [55], N. braziliensis [56] and S. stercoralis [57]. In C. elegans, dauer regulatory GPCR signaling is coupled to downstream IIS and TGF $\beta$ signaling pathways as indicated by the fact that increasing cGMP levels during continuous development elicit production of DAF-7, the TGF $\beta$-like ligand of the heterodimeric receptor 
Table 2 Summary of parasitological findings on structural and functional conservation of dauer-like signaling pathways in parasitic nematodes

\begin{tabular}{|c|c|c|c|c|c|c|c|}
\hline Pathway & Parasite & $\begin{array}{l}\text { Phylogenetic } \\
\text { clade }\end{array}$ & $\begin{array}{l}\text { Genes } \\
\text { conserved? }\end{array}$ & $\begin{array}{l}\text { Genes complement } \\
\text { C. elegans mutants? }\end{array}$ & $\begin{array}{l}\text { Expression } \\
\text { consistent } \\
\text { with dauer } \\
\text { hypothesis? }\end{array}$ & $\begin{array}{l}\text { Function } \\
\text { conserved? }\end{array}$ & References \\
\hline \multirow[t]{3}{*}{ GPCR } & A. caninum & $\mathrm{V}$ & Yes & $? ?$ & $? ?$ & Yes & \multirow[t]{3}{*}[12\bullet\bullet,53-57]{} \\
\hline & N. brasiliensis & $\mathrm{V}$ & Yes & $? ?$ & $? ?$ & Yes & \\
\hline & S. stercoralis & IV & Yes & $? ?$ & Yes & Yes & \\
\hline \multirow[t]{5}{*}{ IIS } & A. caninum & $\mathrm{V}$ & Yes & Yes-daf-16 & $? ?$ & Yes & \multirow{5}{*}{$\begin{array}{c}{[12 \cdot \bullet, 53,60-66} \\
67 \cdot, 68-71]\end{array}$} \\
\hline & A. ceylanicum & $\mathrm{V}$ & Yes & $? ?$ & $? ?$ & Yes & \\
\hline & N. brasiliensis & V & Yes & $? ?$ & $? ?$ & Yes & \\
\hline & H. contortus & $\mathrm{V}$ & Yes & Yes-daf-16 & Yes & Yes & \\
\hline & S. stercoralis & IV & Yes & Yes-daf-16 & Yes & Yes & \\
\hline \multirow[t]{10}{*}{ TGF $\beta$-like } & A. caninum & $\mathrm{V}$ & Yes & $? ?$ & No & $? ?$ & \multirow[t]{10}{*}[12\bullet\bullet,53,73-79,81]{} \\
\hline & N. brasiliensis & $\mathrm{V}$ & Yes & $? ?$ & No & $? ?$ & \\
\hline & He. polygyrus & $\mathrm{V}$ & Yes & $? ?$ & No & $? ?$ & \\
\hline & T. circumcincta & V & Yes & $? ?$ & No & $? ?$ & \\
\hline & H. contortus & V & Yes & $? ?$ & No & $? ?$ & \\
\hline & S. stercoralis & IV & Yes & $? ?$ & No & $? ?$ & \\
\hline & S. ratti & IV & Yes & $? ?$ & No & $? ?$ & \\
\hline & P. trichosuri & IV & Yes & No- $d a f-7$ & No & No & \\
\hline & B. pahangi & III & Yes & $? ?$ & No & $? ?$ & \\
\hline & B. malayi & III & Yes & $? ?$ & No & $? ?$ & \\
\hline \multirow[t]{3}{*}{ Steroid-NHR } & A. caninum & $\mathrm{V}$ & Yes & $? ?$ & $? ?$ & Yes & \multirow{3}{*}{$\begin{array}{l}{[7,12 \bullet \bullet, 53,84,85} \\
\quad 86 \bullet, 87]\end{array}$} \\
\hline & A. ceylanicum & $\mathrm{V}$ & Yes & $? ?$ & $? ?$ & Yes & \\
\hline & S. stercoralis & IV & Yes & $? ?$ & Yes/no & Yes & \\
\hline
\end{tabular}

$G P C R$ G-protein-coupled receptor, IIS insulin/Insulin-like growth factor signaling, $T G F \beta$ transforming growth factor $\beta, N H R$ nuclear hormone receptor, A.-Ancylostoma, N.-Nippostrongylus, He.-Heligmomosoides, T.-Teladorsagia, H.-Haemonchus, S.-Strongyloides, P.—Parastrongyloides, B.-Brugia

comprising DAF-1 and DAF-4. Likewise, increasing cGMP stimulates production of INS-7 and DAF-28, insulin-like peptides (ILPs) and agonists of the insulin-like receptor kinase DAF-2. Strikingly, in addition to stimulating resumption of development, administration of 8-bromo-cGMP to resting iL3 of $S$. stercoralis also upregulates the production of several TGF $\beta$-like ligands in that parasite and of the ILPs Ss-ILP-1 and $S s$-ILP6, putative agonists of $S s$-DAF-2, strongly supporting that GPCR signaling acts upstream of both IIS and TGF $\beta$-like signaling (Fig. $1 \mathrm{D}, \mathrm{E}$ ) [57].

An increasing body of descriptive and experimental data supports a role for IIS in regulating the iL3 of several parasitic nematodes during their infective processes. Genomic and transcriptomic data indicate that the key elements of IIS in C. elegans are conserved in S. stercoralis. These include insulin-like peptides (ILPs), strikingly reduced to seven from the 40 ILPs in C. elegans [53, 58, 59]; Ss-daf-2, encoding an insulin-like receptor kinase [53, 60]; Ss-age-1, $S s-p d k-1$, and Ss-akt-1 encoding cytoplasmic insulin-regulated signaling kinases [53, 61]; and phosphatases or their regulatory subunits encoded in Ss-pten-1 and Ss-pten-2 and in Ss-pptr-1 that modulate the activities of $S s$-AGE-1 and $S s-A K T-1$ (Table 2).
Similarly, key insulin-like signaling intermediates are conserved in the agriculturally important trichostrongyle $H$. contortus [62]. Finally, the homologues of genes encoding the insulin-regulated forkhead transcription factor DAF-16 have been discovered and characterized in S. stercoralis [63], the hookworms A. caninum and Ancylostoma ceylanicum [64], and $H$. contortus [65]. A body of evidence obtained by administering putative inhibitors of insulin-regulated signaling kinases supports that, consistent with its requirement for dauer exit in C. elegans, insulin signaling is necessary for resumption of development by iL3 of parasitic nematodes in the host (Fig. 1 D). The nominal PI3 kinase inhibitor LY294002 blocks resumption of development by iL3 of A. caninum, A. ceylanicum [66], Nippostrongylus brasiliensis [56], and S. stercoralis [61] cultured in permissive host-like conditions. Furthermore, AKT Inhibitor IV blocks resumption of development by cultured $N$. brasiliensis iL3 [56]. Absent from robust functional genomic methods in most parasitic nematodes, evidence of the developmental regulatory capabilities of genes encoding insulin signaling elements in parasitic nematodes has been gathered from studies in which the ability of these parasite genes to rescue loss-of-function mutations in their 
C. elegans homologues has been assessed. Genomic response elements and some downstream target genes of the hookworm homologue Aca-daf-16 have been defined [67•, 68]. These parasite DAF-16 homologues are all able to rescue the dauer arrest when expressed as transgenes in C. elegans carrying the null mutation mu86 in daf-16 (Table 2) [65, 69, 70]. A system for transgenesis in S. stercoralis enabled a more direct interrogation of $S s-d a f-16$ function in that worm [71]. Here, expression patterns of a GFP::Ss-DAF-16 fusion protein in S. stercoralis were virtually identical to those of a similar GFP::Ce-DAF-16 fusion protein in C. elegans [72], and regulation of subcellular localization of Ss-DAF-16 by AKT-mediated phosphorylation was confirmed by introducing putative phospho-null and phospho-mimetic mutations in sequences encoding AKT phosphorylation sites in the transgene. Most significantly, a $g f p:: S s-$ daf-16 transgene construct with phospho-null mutations in all AKT phosphorylation sites and a deletion in the C-terminal domain, which encodes the transactivating functions of forkhead transcription factors, prevented normal iL3 morphogenesis, blocking normal accumulation of vesicles in intestinal cells of post free-living L1 of $S$. stercoralis and promoting initiation of an aberrant L3-L4 molt as well as retention of rhabditiform pharyngeal structure in post free-living L3 [71]. These are characteristics, which in contrast to normal developmentally arrested iL3 with filariform pharynxes, are reminiscent of larvae developing to free-living adults. These phenotypes underscore the requirement for $S s-d a f-16$ function in morphogenesis of iL3 (Fig. 1 E).

Whereas IIS in parasitic nematodes appears to regulate the morphogenesis and development of iL3 during the infective process in a manner consistent with its function in dauer development in C. elegans, homologous TGF $\beta$-like signaling appears to have been adapted for different functions in parasitic nematodes (Fig. 1 G, Table 2). In C. elegans, favorable environmental conditions stimulate the production and secretion of the TGF $\beta$-like ligand DAF-7 from amphidial neurons and its binding to the type I and type II receptors DAF- 1 and DAF-4 in membranes of target cells. Ligation of DAF-1/DAF-4 results in the phosphorylation of receptor SMADs DAF-8 and DAF-14. These rSMADs repress the coSMAD DAF-3 and thus confer a pattern of gene expression leading to continuous reproductive development. Under dauer-inducing conditions, production of DAF-7 is downregulated. In the absence of DAF-1/DAF-4 signaling, the coSMAD DAF-3 is upregulated and, in concert with the Sno/Ski-like transcription factor DAF-5, represses the synthesis of $d a f-7$ and $d a f-8$ conferring a dauer-specific pattern of gene expression. DAF-7-related TGF $\beta$ homologues and some or all of their downstream signaling elements have been discovered in parasitic nematodes representing diverse phylogenetic clades, including hookworms (A. caninum) [73, 74] and trichostrongyles (Heligmosomoides polygyrus, $N$. brasiliensis, Teladorsagia circumcincta, and H. contortus) [75] in clade V; S. stercoralis [53, 76], S. ratti, and
Parastrongyloides trichosuri [77] in clade IV; and Brugia malayi $[78,79]$ in clade III (Table 2). It was postulated early on that in keeping with the dauer hypothesis or "daf-c paradigm" [13], TGF $\beta$-like signaling would regulate formation of parasitic iL3 and that the majority of parasitic nematodes develop in a manner similar to dauer-constitutive (daf-c) mutants in C. elegans DAF-7 [80]. However, although the functions of $d a f-7$ homologues have not been directly interrogated in any parasitic nematode to date, patterns of these homologues' expression in diverse species feature a peak in the iL3 in the majority of species $[12 \bullet \cdot, 53,73,75,78]$ or in another developmentally arrested stage, the microfilaria of $B$. malayi (Table 2) [78]. This is in direct opposition to patterns of daf-7 expression in C. elegans, which is minimal during dauer arrest [8]. Furthermore, Pt-daf-7 from P. trichosuri does not complement a null mutation in C. elegans daf-7 (e1372) [81]. Overall, these findings indicate a function for TGF $\beta$ signaling in parasitic nematodes that is fundamentally different from that of DAF-7 signaling in C. elegans. Among those postulated is a host immunomodulatory function for DAF-7 homologues that facilitates invasion and establishment of infective and postinfective larvae (Fig. $1 \mathrm{G}$ ) [75, 78].

In C. elegans, dauer regulatory insulin-like and TGF $\beta$-like signaling outputs converge to regulate a steroid-NHR signaling pathway involving dafachronic acids [48] and their nuclear receptor, DAF-12. In the presence of ligand, DAF-12 promotes continuous development by $C$. elegans [48] and reverses lifespan extension [47]. In the absence of ligand, DAF-12, in concert with the co-repressor DIN-1, promotes dauer arrest [48] and confers lifespan extension. Genetic epistasis analysis [82] and reverse genetic [83] and biochemical [48] evidence confirm that DAF-12 signaling operates downstream of ILS and TGF $\beta$-like signaling, and likewise, both ILS and TGF $\beta$-like signaling positively regulate biosynthesis of dafachronic acids, principally by upregulating the expression of the cytochrome P450 DAF-9. Like GPCR signaling and ILS, regulatory elements constituting DAF-12 signaling appear to be conserved in parasites and, based on current evidence, to undertake functions that are consistent with their dauer regulatory functions in C. elegans. Homologues of daf12 have been discovered in a number of parasitic nematodes including A. caninum [7, 84], S. stercoralis [85], and Strongyloides papillosus (Table 2), and it is noteworthy that the natural ligands of DAF-12, $\Delta 4$ - and $\Delta 7$-dafachronic acids, can signal through the A. caninum and $S$. stercoralis homologues of this NHR [7]. Moreover, sequence homologues of other key DAF-12 regulatory elements, among them the enzymes catalyzing dafachronic acid synthesis, are conserved in S. stercoralis [53]. Abundance profiles of transcripts encoding DAF-12 signaling elements in S. stercoralis do not strictly conform to expression patterns of their homologues in C. elegans [53]. Nevertheless, there is ample evidence from functional studies that DAF-12 signaling, in some form, 
regulates iL3 morphogenesis and development during the infective process (Fig. 1 D, E). Most strikingly, administration of $\Delta 7$-dafachronic acid, and to a lesser degree $\Delta 4$-dafachronic acid, produces phenotypes in cultured parasitic nematode larvae that are consistent with the ability of these ligands to promote continuous reproductive development and suppress or reverse dauer development in C. elegans. Dafachronic acids promote resumption of development by cultured iL3 of A. caninum and $S$. stercoralis in the absence of host-like cues $[7,57,84]$. Administered $\Delta 7$-dafachronic acid also suppresses the formation of iL 3 in the post free-living generations of S. stercoralis and S. papillosus, giving rise to aberrant post free-living L4 in S. stercoralis and reproductively competent free-living females in S. papillosus [7, 86•, 87]. Similarly, administered $\Delta 7$ dafachronic acid can regulate developmental switching by female larvae of $S$. stercoralis in the postparasitic generation, suppressing direct development to the iL3 and promoting development to free-living females [86•]. Studies with pharmacologic inhibitors provide evidence of endogenous DAF-12 signaling. The cytochrome P450 inhibitor ketoconazole suppresses resumption of feeding by diverse species of parasitic nematode iL3, including A. caninum, $S$. stercoralis, and $N$. brasiliensis, in permissive in vitro culture systems [7, 56, 86॰]. Care is warranted in interpreting these findings, given the limited specificity of ketoconazole and the multiplicity of cytochrome P450s in the parasites studied. In this regard, it is noteworthy that administered $\Delta 7$ dafachronic acid partially rescues the developmental blockade imposed by ketoconazole in S. stercoralis iL3 [86•], lending support to a conclusion of a requirement for endogenous synthesis of a steroid ligand for DAF-12 to stimulate resumption of iL3 development on infection (Fig. 1 D).

\section{Signaling Between Parasitic Nematodes and the Host Immune System}

Parasitic nematodes secrete biologically active proteins into their surroundings in host tissues or gastrointestinal tract, and contemporary bioinformatic and proteomic methods have proven powerful in analyzing these "secretomes" [88-93]. Some of the proteins parasitic nematodes secrete within the host appear capable of directing the host immune response in a manner that is adaptive for the parasite. Exemplary studies in this regard are of the secretome of $S$. ratti [91, 94], which stressed secretory proteins from iL3 and parasitic females that are capable of modulating immune function in host intestinal mucosa. The combined secretomes of $S$. ratti stages investigated to date comprise some 586 proteins [91]. Seventy-nine proteins are secreted by parasitic females of $S$. ratti, among them a prolyl oligopeptidase that appears to be necessary for survival, and a number of small heat shock proteins that are immunogenic to the host interact with the host epithelium or are capable of shifting cytokine production by cultured monocytes to IL-10 in favor of TNF $\alpha$. This suggests that these proteins are capable of directing polarity of the host immune response [91].

Likewise, there is evidence that a protective host immune response may affect subsequent developmental fates in the progeny of parasitic adult worms. In a striking example of this, $S$. ratti larvae exiting a host that is mounting an immune response to the parasite are more likely to develop to freeliving males and females, as opposed to iL3, than larvae exiting naive hosts $[95,96]$. Given the roles that amphidial neuron pairs ASF and ASI play in developmental switching by $S$. stercoralis, it is logical to hypothesize that these neurons receive signals of mounting immunity that contribute to commitment to free-living development $[95,96]$. However, in view of the fact that a history of dauer development is imprinted in the form of epigenetic marks on subsequent generations of developing C. elegans larvae [97], the possibility that the effect of host immunity on development by subsequent generations of parasitic nematode larvae is epigenetically controlled should also be considered.

\section{Conclusion and Future Directions}

Currently, the mechanisms governing the innate behaviors that orient infective parasitic nematode larvae can only be surmised based on knowledge of the interplay between mechanosensory neurons and muscles involved in progressive motility in C. elegans [98]. However, the technology now exists to test relevant hypotheses using microlaser cell ablation and transgene-mediated lysis of specific cells in appropriate parasite models such as Strongyloides spp. [20, 99]. By contrast, neuronal control of taxes by infective larvae that bring them in contact with a host is better understood thanks to careful studies of neuroanatomy in the larvae of soiltransmitted parasitic nematodes and the microlaser ablation studies that these enable $[20,21]$. It may again be surmised from $C$. elegans science that impulses within crucial sensory neurons in parasites are transduced by GPCR signaling, but this has not been tested. Overall, molecular mechanisms that are required for host finding and acquisition could theoretically become the bases for preventative medications, but it is unlikely that such interventions would be practical in combatting medically important nematode parasitisms, which are generally infections associated with extreme poverty. On the other hand, specific signal transduction mechanisms governing the infective process that are adapted from those regulating dauer larval recovery and adult lifespan in C. elegans have supported this "dauer hypothesis" in part $[12 \bullet \cdot]$ and have revealed points of regulation by small molecules that could constitute novel chemotherapeutic targets. The most obvious of these is signaling through homologues 
of the DAF-12 nuclear receptor by dafachronic acid-related steroids [7, 84, 86•]. Cell-based reporter assays incorporating DAF-12 homologues from parasitic nematodes have already been developed [7] and could constitute probes to identify natural ligands of parasite DAF-12 homologues and form the bases for high-throughput screens for both agonistic and antagonistic ligands of these NHRs. "Hits" from such high capacity screening could constitute leads in the search for new drugs to prevent establishment by infective larvae and hasten expulsion of adult worms in a wide range of parasitic nematode infections or prevent potentially fatal hyperinfection by $S$. stercoralis. Finally, thanks to efforts to define the secretomes of parasitic nematodes within their definitive hosts and to assess the roles of these in modulating the host immune response, a picture of how nematodes establish and maintain chronic infection on the one hand, but also contribute to immunological homeostasis in the host, is now emerging with greater clarity [91]. The molecular mechanisms involved in signaling between nematode parasites and their hosts' immune systems could constitute new immunotherapies, not only for nematode parasitosis but also for inflammatory diseases of diverse etiology [100].

\section{Compliance with Ethical Standards}

Conflict of Interest Dr. Lok reports grants from the US National Institutes of Health during the conduct of the study.

Human and Animal Rights and Informed Consent This article does not contain any studies with human or animal subjects performed by the author.

Open Access This article is distributed under the terms of the Creative Commons Attribution 4.0 International License (http:// creativecommons.org/licenses/by/4.0/), which permits unrestricted use, distribution, and reproduction in any medium, provided you give appropriate credit to the original author(s) and the source, provide a link to the Creative Commons license, and indicate if changes were made.

\section{References}

Papers of particular interest, published recently, have been highlighted as:

- Of importance

- Of major importance

1. Hotez PJ, Herricks JR. Helminth elimination in the pursuit of sustainable development goals: a "worm index" for human development. PLoS Negl Trop Dis. 2015;9(4):e0003618. doi:10.1371 journal.pntd.0003618.

2. Gilleard JS. Haemonchus contortus as a paradigm and model to study anthelmintic drug resistance. Parasitology. 2013;140(12): 1506-22. doi:10.1017/S0031182013001145.

3. Rose H, Rinaldi L, Bosco A, Mavrot F, de Waal T, Skuce P, et al. Widespread anthelmintic resistance in European farmed ruminants: a systematic review. Vet Rec. 2015;176(21):546. doi:10.1136/vr.102982.

4. Martin RJ, Robertson AP, Buxton SK, Beech RN, Charvet CL, Neveu C. Levamisole receptors: a second awakening. Trends Parasitol. 2012;28(7):289-96. doi:10.1016/j.pt.2012.04.003.

5. Wolstenholme AJ. Recent progress in understanding the interaction between avermectins and ligand-gated ion channels: putting the pests to sleep. Invert Neurosci. 2010;10(1):5-10. doi:10.1007 /s10158-010-0105-y.

6. Martin RJ. Modes of action of anthelmintic drugs. Vet J. 1997;154(1):11-34.

7. Wang Z, Zhou XE, Motola DL, Gao X, Suino-Powell K, Conneely A, et al. Identification of the nuclear receptor DAF-12 as a therapeutic target in parasitic nematodes. Proc Natl Acad Sci U S A. 2009;106(23):9138-43. doi:10.1073/pnas.0904064106.

8. Gumienny TL, Savage-Dunn C. TGF-beta signaling in C. elegans. In: Community $\mathrm{TCe}$, editor. WormBook: the online review of C. elegans biology. 2013/08/03 ed2013. p. 1-34.

9. Murphy CT, Hu PJ. Insulin/insulin-like growth factor signaling in C. elegans. In: Community TCeR, editor. WormBook: the online review of C. elegans biology. 2014/01/08 ed2013. p. 1-43.

10. Antebi A. Nuclear receptor signal transduction in C. elegans. In: Community TCeR, editor. WormBook: the online review of C. elegans biology. 2015/06/13 ed2015. p. 1-49.

11. Koelle MR. Neurotransmitter signaling through heterotrimeric $G$ proteins: insights from studies in C. elegans. WormBook: the online review of C. elegans biology. 2016/03/05 ed2016. p. 1-78.

12.• Crook M. The dauer hypothesis and the evolution of parasitism: 20 years on and still going strong. Int J Parasitol. 2014;44(1):1-8. doi:10.1016/j.ijpara.2013.08.004. A very informative contemporary review of dauer-like signaling in parasitic nematodes and, more importantly, an authoritative critique of the "Dauer Hypothesis" of morphogenesis and development of infective parasitic nematode larvae.

13. Hotez P, Hawdon J, Schad GA. Hookworm larval infectivity, arrest and amphiparatenesis: the Caenorhabditis elegans Daf-c paradigm. Parasitol Today. 1993;9(1):23-6.

14. Chaisson KE, Hallem EA. Chemosensory behaviors of parasites. Trends Parasitol. 2012;28(10):427-36. doi:10.1016/j. pt.2012.07.004.

15. Croll NA. Behavior of larval nematodes. In: Canning EU, Wright CA, editors. Behavioral aspects of parasite transmission. London: Academic; 1972. p. 31-52.

16. Rees G. Observations on the vertical migrations of the third-stage larva of Haemonchus contortus (Rud.) on experimental plots of Lolium perenne S24, in relation to meteorological and micrometeorological factors. Parasitology. 1950;40(1-2):127-43.

17. Sciacca J, Ketschek A, Forbes WM, Boston R, Guerrero J, Ashton FT, et al. Vertical migration by the infective larvae of three species of parasitic nematodes: is the behaviour really a response to gravity? Parasitology. 2002;125(Pt 6):553-60.

18. Ketschek AR, Freeman AS, Boston R, Habecker PL, Ashton FT, Schad GA. Vertical migratory behavior of the infective third-stage larvae of Oesophagostomum dentatum. Vet Parasitol. 2004;123(3-4):215-21.

19. Torr P, Heritage S, Wilson MJ. Vibrations as a novel signal for host location by parasitic nematodes. Int J Parasitol. 2004;34(9):997-9.

20. Ashton FT, Bhopale VM, Holt D, Smith G, Schad GA. Developmental switching in the parasitic nematode Strongyloides stercoralis is controlled by the ASF and ASI amphidial neurons. J Parasitol. 1998;84:691-5.

21. Bargmann CI, Avery L. Laser killing of cells in Caenorhabditis elegans. In: Epstein HF, Shakes DC, editors. Caenorhabditis elegans: Modern biological analysis of an organism. Methods in cell biology. San Diego: Academic Press; 1995. p. 225-50. 
22. Chelur DS, Chalfie M. Targeted cell killing by reconstituted caspases. Proc Natl Acad Sci U S A. 2007;104(7):2283-8.

23. Granzer M, Haas W. Host-finding and host recognition of infective Ancylostoma caninum larvae. Int J Parasitol. 1991;21(4):429-40.

24. Lopez PM, Boston R, Ashton FT, Schad GA. The neurons of class ALD mediate thermotaxis in the parasitic nematode, Strongyloides stercoralis. Int J Parasitol. 2000;30(10):1115-21.

25. Sciacca J, Forbes WM, Ashton FT, Lombardini E, Gamble HR, Schad GA. Response to carbon dioxide by the infective larvae of three species of parasitic nematodes. Parasitol Int. 2002;51(1):53-62.

26. Castelletto ML, Gang SS, Okubo RP, Tselikova AA, Nolan TJ, Platzer EG, et al. Diverse host-seeking behaviors of skinpenetrating nematodes. PLoS Pathog. 2014;10(8):e1004305. doi:10.1371/journal.ppat.1004305. Novel conclusions are that host preference is a stronger determinant of attract profiles than phylogeny. Also noteworthy is the finding of conservation of host attractant sensitivities between parasitic nematodes and hematophagous arthropods.

27. Forbes WM, Ashton FT, Boston R, Zhu X, Schad GA. Chemoattraction and chemorepulsion of Strongyloides stercoralis infective larvae on a sodium chloride gradient is mediated by amphidial neuron pairs ASE and ASH, respectively. Vet Parasitol. 2004;120(3):189-98.

28. Bargmann CI, Mori I. Chemotaxis and thermotaxis. In: Riddle DL, Blumenthal T, Meyer BJ, Priess JR, editors. C. elegans II. Cold Spring Harbor: Cold Spring Harbor Laboratory Press; 1997. p. 717-38.

29. Safer D, Brenes M, Dunipace S, Schad G. Urocanic acid is a major chemoattractant for the skin-penetrating parasitic nematode Strongyloides stercoralis. Proc Natl Acad Sci U S A. 2007;104(5):1627-30. doi:10.1073/pnas.0610193104.

30. Ketschek AR, Joseph R, Boston R, Ashton FT, Schad GA. Amphidial neurons ADL and ASH initiate sodium dodecyl sulphate avoidance responses in the infective larva of the dog hookworm Anclyostoma caninum. Int J Parasitol. 2004;34(12):1333-6.

31. Troemel ER. Chemosensory signaling in C. elegans. Bioessays. 1999;21(12):1011-20.

32. Riddle DL, Albert PS. Genetic and environmental regulation of dauer larva development. In: Riddle DL, Blumenthal T, Meyer BJ, Priess JR, editors. C. elegans II. 2nd ed. Cold Spring Harbor: Cold Spring Harbor Laboratory Press; 1997.

33. Hu PJ. Dauer. WormBook. 2007:1-19. doi:10.1895 /wormbook.1.144.1.

34. Yamada M, Matsuda S, Nakazawa M, Arizono N. Speciesspecific differences in heterogonic development of serially transferred free-living generations of Strongyloides planiceps and Strongyloides stercoralis. J Parasitol. 1991;77:592-4.

35. Grant WN, Stasiuk S, Newton-Howes J, Ralston M, Bisset SA, Heath DD, et al. Parastrongyloides trichosuri, a nematode parasite of mammals that is uniquely suited to genetic analysis. Int $\mathrm{J}$ Parasitol. 2006;36(4):453-66. doi:10.1016/j.ijpara.2005.11.009.

36. Viney ME. Developmental switching in the parasitic nematode Strongyloides ratti. Proc R Soc Lond Ser B. 1996;263:201-8.

37. Nwaorgu OC. The development of the free-living stages of Strongyloides papillosus. I. Effect of temperature on the development of the heterogonic and homogonic nematodes in faecal culture. Vet Parasitol. 1983;13(3):213-23.

38. Nolan TJ, Brenes M, Ashton FT, Zhu X, Forbes WM, Boston R, et al. The amphidial neuron pair ALD controls the temperaturesensitive choice of alternative developmental pathways in the parasitic nematode, Strongyloides stercoralis. Parasitology. 2004;129(Pt 6):753-9.

39. Arizono N. Studies on the free-living generations of Strongyloides planiceps Rogers, 1943 I. Effects of quantity of food and population density on the developmental types. Jpn J Parasitol. 1976;25: 274-82.
40. Minematsu T, Mimori T, Tanaka M, Tada I. The effect of fatty acids on the developmental direction of Strongyloides ratti firststage larvae. J Helminthol. 1989;63(2):102-6.

41. Moncol DJ, Triantaphyllou AC. Stronglyoides ransomi: factors influencing the in vitro development of the free-living generation. J Parasitol. 1978;64(2):220-5.

42. Kim K, Sato K, Shibuya M, Zeiger DM, Butcher RA, Ragains JR, et al. Two chemoreceptors mediate developmental effects of dauer pheromone in C. elegans. Science. 2009;326(5955):994-8. doi:10.1126/science. 1176331 .

43. Zwaal RR, Mendel JE, Sternberg PW, Plasterk RH. Two neuronal G proteins are involved in chemosensation of the Caenorhabditis elegans dauer-inducing pheromone. Genetics. 1997;145(3):715-27.

44. Hahm JH, Kim S, Paik YK. Endogenous cGMP regulates adult longevity via the insulin signaling pathway in Caenorhabditis elegans. Aging Cell. 2009;8(4):473-83. doi:10.1111/j.14749726.2009.00495.x.

45. Inglis PN, Ou G, Leroux MR, Scholey JM. The sensory cilia of Caenorhabditis elegans. WormBook: the online review of C. elegans biology. 2007/12/01 ed2007. p. 1-22.

46. Bethke A, Fielenbach N, Wang Z, Mangelsdorf DJ, Antebi A. Nuclear hormone receptor regulation of microRNAs controls developmental progression. Science. 2009;324(5923):95-8. doi:10.1126/science.1164899.

47. Gerisch B, Rottiers V, Li D, Motola DL, Cummins CL, Lehrach H, et al. A bile acid-like steroid modulates Caenorhabditis elegans lifespan through nuclear receptor signaling. Proc Natl Acad Sci U S A. 2007;104(12):5014-9. doi:10.1073/pnas.0700847104.

48. Motola DL, Cummins CL, Rottiers V, Sharma KK, Li T, Li Y, et al. Identification of ligands for DAF-12 that govern dauer formation and reproduction in C. elegans. Cell. 2006;124(6):120923. doi:10.1016/j.cell.2006.01.037.

49. Schaedel ON, Gerisch B, Antebi A, Sternberg PW. Hormonal signal amplification mediates environmental conditions during development and controls an irreversible commitment to adulthood. PLoS Biol. 2012;10(4):e1001306. doi:10.1371/journal. pbio. 1001306.

50. Wollam J, Magner DB, Magomedova L, Rass E, Shen Y, Rottiers $\mathrm{V}$, et al. A novel 3-hydroxysteroid dehydrogenase that regulates reproductive development and longevity. PLoS Biol. 2012;10(4): e1001305. doi:10.1371/journal.pbio.1001305.

51. Wollam J, Magomedova L, Magner DB, Shen Y, Rottiers V, Motola DL, et al. The Rieske oxygenase DAF-36 functions as a cholesterol 7-desaturase in steroidogenic pathways governing longevity. Aging Cell. 2011;10(5):879-84. doi:10.1111/j.14749726.2011.00733.x.

52. Hunt VL, Tsai IJ, Coghlan A, Reid AJ, Holroyd N, Foth BJ, et al. The genomic basis of parasitism in the Strongyloides clade of nematodes. Nat Genet. 2016;48(3):299-307. doi:10.1038/ng.3495.

53. Stoltzfus JD, Minot S, Berriman M, Nolan TJ, Lok JB. RNAseq analysis of the parasitic nematode Strongyloides stercoralis reveals divergent regulation of canonical dauer pathways. PLoS Negl Trop Dis. 2012;6(10):e1854. doi:10.1371/journal. pntd.0001854.

54. Massey Jr HC, Ball CC, Lok JB. PCR amplification of putative gpa-2 and gpa-3 orthologs from the (A + T)-rich genome of Strongyloides stercoralis. Int J Parasitol. 2001;31(4):377-83.

55. Hawdon JM, Datu B. The second messenger cyclic GMP mediates activation in Ancylostoma caninum infective larvae. Int $\mathrm{J}$ Parasitol. 2003;33(8):787-93.

56. Huang SC, Chan DT, Smyth DJ, Ball G, Gounaris K, Selkirk ME. Activation of Nippostrongylus brasiliensis infective larvae is regulated by a pathway distinct from the hookworm Ancylostoma caninum. Int J Parasitol. 2010;40(14):1619-28. doi:10.1016/j. ijpara.2010.06.004. 
57. Stoltzfus JD, Bart SM, Lok JB. cGMP and NHR signaling coregulate expression of insulin-like peptides and developmental activation of infective larvae in Strongyloides stercoralis. PLoS Pathog. 2014;10(7):e1004235. doi:10.1371/journal. ppat. 1004235 .

58. Li W, Kennedy SG, Ruvkun G. daf-28 encodes a C. elegans insulin superfamily member that is regulated by environmental cues and acts in the DAF-2 signaling pathway. Genes Dev. 2003;17(7): 844-58. doi:10.1101/gad.1066503.

59. Pierce SB, Costa M, Wisotzkey R, Devadhar S, Homburger SA, Buchman AR, et al. Regulation of DAF-2 receptor signaling by human insulin and ins-1, a member of the unusually large and diverse C. elegans insulin gene family. Genes Dev. 2001;15(6): 672-86. doi:10.1101/gad.867301.

60. Massey Jr HC, Ranjit N, Stoltzfus JD, Lok JB. Strongyloides stercoralis daf-2 encodes a divergent ortholog of Caenorhabditis elegans DAF-2. Int J Parasitol. 2013;43(7):515-20. doi:10.1016/j. ijpara.2013.01.008.

61. Stoltzfus JD, Massey Jr HC, Nolan TJ, Griffith SD, Lok JB. Strongyloides stercoralis age-1: a potential regulator of infective larval development in a parasitic nematode. PLoS One. 2012;7(6): e38587. doi:10.1371/journal.pone.0038587.

62. Mohandas N, Hu M, Stroehlein AJ, Young ND, Sternberg PW, Lok JB, et al. Reconstruction of the insulin-like signalling pathway of Haemonchus contortus. Parasit Vectors. 2016;9:64. doi:10.1186/s13071-016-1341-8.

63. Massey Jr HC, Nishi M, Chaudhary K, Pakpour N, Lok JB. Structure and developmental expression of Strongyloides stercoralis fktf-1, a proposed ortholog of daf-16 in Caenorhabditis elegans. Int J Parasitol. 2003;33(13):1537-44.

64. Gao X, Frank D, Hawdon JM. Molecular cloning and DNA binding characterization of DAF-16 orthologs from Ancylostoma hookworms. Int J Parasitol. 2009;39(4):407-15. doi:10.1016/j. ijpara.2008.09.005.

65. Hu M, Lok JB, Ranjit N, Massey Jr HC, Sternberg PW, Gasser RB. Structural and functional characterisation of the fork head transcription factor-encoding gene, $H c$-daf-16, from the parasitic nematode Haemonchus contortus (Strongylida). Int J Parasitol. 2010;40(4):405-15. doi:10.1016/j.ijpara.2009.09.005.

66. Brand A, Hawdon JM. Phosphoinositide-3-OH-kinase inhibitor LY294002 prevents activation of Ancylostoma caninum and Ancylostoma ceylanicum third-stage infective larvae. Int $\mathrm{J}$ Parasitol. 2004;34(8):909-14. doi:10.1016/j.ijpara.2004.04.003.

67. Gao X, Goggin K, Dowling C, Qian J, Hawdon JM. Two potential hookworm DAF-16 target genes, SNR-3 and LPP-1: gene structure, expression profile, and implications of a cis-regulatory element in the regulation of gene expression. Parasit Vectors. 2015;8: 14. doi:10.1186/s13071-014-0609-0. The first investigation of specific DAF-16 regulated genes in a parasitic nematode, Ancylostoma caninum. Provides insights into the likely developmental functions of a core small nuclear ribonucleoprotein and a lipid phosphate phosphohydrolase encoded in two of these, Aca-snr-3 and Aca-ipp-1. Generally supports a role for IIS in post-infective development of $A$. caninum.

68. Gao X, Wang Z, Martin J, Abubucker S, Zhang X, Mitreva M, et al. Identification of hookworm DAF-16/FOXO response elements and direct gene targets. PLoS One. 2010;5(8):e12289. doi:10.1371/journal.pone.0012289.

69. Gelmedin V, Brodigan T, Gao X, Krause M, Wang Z, Hawdon JM. Transgenic $C$. elegans dauer larvae expressing hookworm phospho null DAF-16/FoxO exit dauer. PLoS One. 2011;6(10): e25996. doi:10.1371/journal.pone.0025996.

70. Massey Jr HC, Bhopale MK, Li X, Castelletto M, Lok JB. The fork head transcription factor FKTF-1b from Strongyloides stercoralis restores DAF-16 developmental function to mutant
Caenorhabditis elegans. Int J Parasitol. 2006;36(3):347-52. doi:10.1016/j.ijpara.2005.11.007.

71. Castelletto ML, Massey Jr HC, Lok JB. Morphogenesis of Strongyloides stercoralis infective larvae requires the DAF-16 ortholog FKTF-1. PLoS Pathog. 2009;5(4):e1000370. doi:10.1371/journal.ppat.1000370.

72. Lee RY, Hench J, Ruvkun G. Regulation of C. elegans DAF-16 and its human ortholog FKHRL1 by the daf-2 insulin-like signaling pathway. Curr Biol. 2001;11(24):1950-7.

73. Freitas TC, Arasu P. Cloning and characterisation of genes encoding two transforming growth factor-beta-like ligands from the hookworm, Ancylostoma caninum. Int J Parasitol. 2005;35(14):1477-87. doi:10.1016/j.ijpara.2005.07.005.

74. Brand AM, Varghese G, Majewski W, Hawdon JM. Identification of a DAF-7 ortholog from the hookworm Ancylostoma caninum. Int J Parasitol. 2005;35(14):1489-98. doi:10.1016/j. ijpara.2005.07.004.

75. McSorley HJ, Grainger JR, Harcus Y, Murray J, Nisbet AJ, Knox DP, et al. daf-7-related TGF-beta homologues from Trichostrongyloid nematodes show contrasting life-cycle expression patterns. Parasitology. 2010;137(1):159-71. doi:10.1017 /S0031182009990321.

76. Massey HC, Castelletto ML, Bhopale VM, Schad GA, Lok JB. Sst-tgh-1 from Strongyloides stercoralis encodes a proposed ortholog of daf-7 in Caenorhabditis elegans. Mol Biochem Parasitol. 2005;142(1):116-20. doi:10.1016/j. molbiopara.2005.03.004.

77. Crook M, Thompson FJ, Grant WN, Viney ME. daf-7 and the development of Strongyloides ratti and Parastrongyloides trichosuri. Mol Biochem Parasitol. 2005;139(2):213-23. doi:10.1016/j.molbiopara.2004.11.010.

78. Gomez-Escobar N, Gregory WF, Maizels RM. Identification of $\operatorname{tgh}$-2, a filarial nematode homolog of Caenorhabditis elegans daf7 and human transforming growth factor beta, expressed in microfilarial and adult stages of Brugia malayi. Infect Immun. 2000;68(11):6402-10.

79. Gomez-Escobar N, van den Biggelaar A, Maizels R. A member of the TGF-beta receptor gene family in the parasitic nematode Brugia pahangi. Gene. 1997;199(1-2):101-9.

80. Rajan TV. A hypothesis for the tissue specificity of nematode parasites. Exp Parasitol. 1998;89(1):140-2. doi:10.1006 /expr.1998.4264.

81. Crook M, Grant K, Grant WN. Failure of Parastrongyloides trichosuri daf-7 to complement a Caenorhabditis elegans daf-7 (e1372) mutant: implications for the evolution of parasitism. Int $\mathrm{J}$ Parasitol. 2010;40(14):1675-83. doi: $10.1016 / \mathrm{j}$. ijpara.2010.07.003.

82. Dumas KJ, Guo C, Wang X, Burkhart KB, Adams EJ, Alam H, et al. Functional divergence of dafachronic acid pathways in the control of C. elegans development and lifespan. Dev Biol. 2010;340(2):605-12. doi:10.1016/j.ydbio.2010.02.022.

83. Gerisch B, Antebi A. Hormonal signals produced by DAF-9/cytochrome $\mathrm{P} 450$ regulate $C$. elegans dauer diapause in response to environmental cues. Development. 2004;131(8):1765-76. doi: $10.1242 /$ dev.01068.

84. Zhi X, Zhou XE, Melcher K, Motola DL, Gelmedin V, Hawdon J, et al. Structural conservation of ligand binding reveals a bile acidlike signaling pathway in nematodes. J Biol Chem. 2012;287(7): 4894-903. doi:10.1074/jbc.M111.315242.

85. Siddiqui AA, Stanley CS, Skelly PJ, Berk SL. A cDNA encoding a nuclear hormone receptor of the steroid/thyroid hormonereceptor superfamily from the human parasitic nematode Strongyloides stercoralis. Parasitol Res. 2000;86(1):24-9.

86. Albarqi MM, Stoltzfus JD, Pilgrim AA, Nolan TJ, Wang Z, Kliewer SA, et al. Regulation of life cycle checkpoints and developmental activation of infective larvae in Strongyloides stercoralis 
by dafachronic acid. PLoS Pathog. 2016;12(1):e1005358. doi:10.1371/journal.ppat.1005358. A comprehensive study of the effects of administered $\Delta 7$-dafachronic acid and endogenous steroid-NHR signaling on determination of preinfective larval fates and resumption of infective larval development in S. stercoralis. Rescue of ketoconazole-inhibited iL3 activation by $\Delta 7$-dafachronic acid bolsters the requirement for biosynthesis of a Ss-DAF-12 ligand in crucial phase of the infective process.

87. Ogawa A, Streit A, Antebi A, Sommer RJ. A conserved endocrine mechanism controls the formation of dauer and infective larvae in nematodes. Curr Biol. 2009;19(1):67-71. doi:10.1016/j. cub.2008.11.063.

88. Eberle R, Brattig NW, Trusch M, Schluter H, Achukwi MD, Eisenbarth A, et al. Isolation, identification and functional profile of excretory-secretory peptides from Onchocerca ochengi. Acta Trop. 2015;142:156-66. doi:10.1016/j. actatropica.2014.11.015.

89. Morchon R, Gonzalez-Miguel J, Carreton E, Kramer LH, Valero L, Montoya-Alonso JA, et al. Proteomic analysis of the somatic and surface compartments from Dirofilaria immitis adult worms. Vet Parasitol. 2014;203(1-2):144-52. doi:10.1016/j. vetpar.2014.02.005.

90. Sassi AJ, Geary JF, Leroux LP, Moorhead AR, Satti M, Mackenzie CD, et al. Identification of Dirofilaria immitis proteins recognized by antibodies from infected dogs. J Parasitol. 2014;100(3):364-7. doi:10.1645/13-437.1.

91. Soblik H, Younis AE, Mitreva M, Renard BY, Kirchner M, Geisinger F, et al. Life cycle stage-resolved proteomic analysis of the excretome/secretome from Strongyloides ratti-identification of stage-specific proteases. Mol Cell Proteomics. 2011;10(12):M111 010157. doi:10.1074/mcp.M111.010157.

92. Smith SK, Nisbet AJ, Meikle LI, Inglis NF, Sales J, Beynon RJ, et al. Proteomic analysis of excretory/secretory products released by Teladorsagia circumcincta larvae early post-infection. Parasite Immunol. 2009;31(1):10-9. doi:10.1111/j.13653024.2008.01067.x.

93. Hewitson JP, Harcus YM, Curwen RS, Dowle AA, Atmadja AK, Ashton PD, et al. The secretome of the filarial parasite, Brugia malayi: proteomic profile of adult excretory-secretory products. Mol Biochem Parasitol. 2008;160(1):8-21. doi:10.1016/j. molbiopara.2008.02.007.

94. Younis AE, Geisinger F, Ajonina-Ekoti I, Soblik H, Steen H, Mitreva M, et al. Stage-specific excretory-secretory small heat shock proteins from the parasitic nematode Strongyloides rattiputative links to host's intestinal mucosal defense system. FEBS J. 2011;278(18):3319-36. doi:10.1111/j.1742-4658.2011.08248.x.

95. Gemmill AW, Viney ME, Read AF. Host immune status determines sexuality in a parasitic nematode. Evolution. 1997;51:393-401.

96. Harvey SC, Gemmill AW, Read AF, Viney ME. The control of morph development in the parasitic nematode Strongyloides ratti. Proc Biol Sci. 2000;267(1457):2057-63. doi:10.1098 /rspb.2000.1249.

97. Hall SE, Beverly M, Russ C, Nusbaum C, Sengupta P. A cellular memory of developmental history generates phenotypic diversity in C. elegans. Curr Biol. 2010;20(2):149-55. doi:10.1016/j. cub.2009.11.035.

98. Goodman MB. Mechanosensation. WormBook. 2006:1-14. doi:10.1895/wormbook.1.62.1.

99. Lok JB, Shao H, Massey HC, Li X. Transgenesis in Strongyloides and related parasitic nematodes: historical perspectives, current functional genomic applications and progress towards gene disruption and editing. Parasitology. 2016:1-16. doi:10.1017 /S0031182016000391.

100. Szkudlapski D, Labuzek K, Pokora Z, Smyla N, Gonciarz M, Mularczyk A, et al. The emerging role of helminths in treatment of the inflammatory bowel disorders. J Physiol Pharmacol. 2014;65(6):741-51. 